\title{
Comparison of Flow Resistance Characteristics and Placement of Two Endotracheal Tubes
}

\author{
Girish G Deshpande MD, John E Sanford RRT, and Sandeep Tripathi MD
}

\begin{abstract}
BACKGROUND: In a traditional endotracheal tube (ETT), there is a linear outward pull through its attachment to the ventilator tubing that leads to risk of accidental dislodgement. This study was conducted to assess the ETT flow characteristics and to evaluate providers' intubation experience using two ETT's in a simulated setting. METHODS: Respiratory pressure-volume dynamics for the 2 ETTs were studied in a simulation laboratory by using 3 different flow settings and 2 different test lungs. The time taken for successful intubation on a mannikin was compared by direct observation of 33 separate intubation attempts by 11 different providers. Comfort with intubation by using both tubes was assessed with a Likert scale-based survey. The potential increase in physical and cognitive work load of nurses and respiratory therapists was assessed by the NASA task load index. RESULTS: There were slightly lower average tidal volumes delivered with SecureTube compared with the standard tube at different peak inspiratory pressures. Similarly, the same tidal volume delivered with a different flow and bag compliance required slightly higher peak inspiratory pressure compared with the standard ETT. Among providers, there was no difference in the average time to intubate when using either tube. All survey respondents $(N=11)$ rated intubation attempts with the SecureTube to be very easy compared with the standard tube. The NASA task load index $(N=26)$ showed very low task loads on all the tasks. CONCLUSIONS: There was minimal impact on flow resistance on pressure or volume with the SecureTube compared with the standard tube. Most providers felt comfortable intubating with the SecureTube and took a comparable amount of time to intubate in a simulated setting. We observed low task load scores for securement, maintenance, and manipulation per nurses and respiratory therapists. Key words: endotracheal tube; unplanned extubation; tracheal intubation complications; adults; pediatrics; NASA task load index. [Respir Care 2018;63(9):1118-1124. () 2018 Daedalus Enterprises]
\end{abstract}

\section{Introduction}

Unplanned extubations are among the most common and serious complications of tracheal intubation. ${ }^{1,2}$ The incidence of unplanned extubation varies from $3 \%$ to $16 \%$ in adults ${ }^{3,4}$ and $2.7 \%$ to $13 \%$ in pediatric patients. ${ }^{5}$ There are several quality improvement studies in pediatric and

Drs Deshpande and Tripathi are affiliated with Division of Pediatric Critical Care, Department of Pediatrics, University of Illinois College of Medicine, Peoria, Illinois. Mr Sanford is affiliated with Department of Respiratory Therapy, OSF St Francis Medical Center, Peoria, Illinois.

The design of the SecureTube was funded through a "Proof of Concept" Chancellor Innovation Grant, University of Illinois, Chicago, Illinois (2013).

Dr Deshpande holds the patent for the SecureTube. Dr Tripathi and $\mathrm{Mr}$ Sanford have disclosed no conflicts of interest. adult populations when using different interventions, which showed decreased unplanned extubation rates in the hospital. ${ }^{6-10}$ Despite these studies, no interventions have been shown consistently to be effective in preventing unplanned extubations, which remains a significant hospital-acquired condition with high health-care cost. ${ }^{11,12}$

There are a wide variety of endotracheal tubes (ETT) available from different manufacturers, such as tubes with a suction port above the cuff or silver-impregnated tubes to decrease the colonization of the ETT. However, the basic design of the ETT has remained the same for several

Correspondence: Girish Deshpande MD, Children's Hospital of Illinois, 530 NE Glen Oak Ave, Peoria, IL 61637. E-mail: girish@uic.edu.

DOI: $10.4187 /$ respcare. 05813 


\section{Flow Resistance and Placement of ETTs}

decades. Traditional ETTs are secured at only one location on the tube with use of tape or other device to the patient's face. The ventilator end of the ETT is usually fitted with a Y-adapter in which one limb of the $\mathrm{Y}$ is connected to ventilator tubing and the other limb is connected to the in-line suction tubing. An end-tidal carbon dioxide monitor and tidal volume $\left(\mathrm{V}_{\mathrm{T}}\right)$ measuring sensors are often interposed between the ETT adapter and ventilator tubing for closer monitoring. These monitoring modalities, although being clinically valuable, add a considerable amount of weight at the end of the ETT, creating a constant pull in an outward direction, making the ETT vulnerable for unplanned extubation. This outward pull is further enhanced by side-to-side movement of the patient's head, which causes an in-and-out movement of the ETT, loosening the holder or tape as it becomes wet from oral secretions. The outward pull from the tubing and the loose tape and/or holder makes the ETT vulnerable for accidental extubation, especially when combined with lightening of sedation or movement of the patient. Commercial ETT holders have also been shown to exert greater force on the patient's face, which may result in a higher risk of pressure ulcers. ${ }^{13}$

A new ETT design, the SecureTube (see footnote 1), has been described (Fig. 1). This tube has 2 ports, the straight port and the side (ventilator) port. The straight port is connected to in-line suction, and the side port is connected to the ventilator tubing and is secured to the patient's cheek by using a special holder (Fig. 2). This design changes the direction of the pull sideward, perpendicular to the long axis of the ETT, with the theoretical reduced possibility of accidental dislodgement. Two securing locations also make the tube more stable and may offer protection from accidental dislodgement.

The addition of the side port, however, may change the resistance characteristics of the tube, which, thus, changes the volume and/or pressure delivered to the patient, and the altered design may affect the intubation process and securement by the providers. The objectives of this study were the following: (1) to study the impact of the side port on ventilator pressure and/or volume characteristics; (2) to evaluate the intubation experience of clinicians, including the time required for successful intubation; and (3) to evaluate the understanding of the securement and manipulation or adjustment of the SecureTube by nurses and respiratory therapists, and to compare it with a traditional ETT in a simulated setting (Fig. 3). The study was reviewed by the University of Illinois College of Medicine Institutional Review Board and was deemed to be exempt research. We hypothesized that the SecureTube would perform as well as a traditional tube (Mallinckrodt, Mansfield, Massachusetts) with regard to intubation timing (objective measure) and experience by the providers (subjective measure), and in a comparison of changes in pressures and volumes in different modes of ventilation when using test lungs.

\section{QUICK LOOK}

\section{Current knowledge}

The traditional endotracheal tube (ETT) design places an outward linear pull on the ETT by ventilator attachments, which thereby posing a risk of accidental dislodgement. The basic design of the ETT has remained unchanged for several decades.

\section{What this paper contributes to our knowledge}

We described a new design for the ETT (SecureTube). Ease of placement during simulated intubations compared with a traditional ETT. Flow dynamic data showed a mild increase in air-flow resistance compared to the traditional ETT.

\section{Methods}

The resistive characteristics of the tubes were studied in a simulated setting by using an AVEA ventilator (Viasys Avea CareFusion, San Diego, California). The delivered $\mathrm{V}_{\mathrm{T}}$ at set $\Delta \mathrm{P}$ (peak inspiratory pressure [PIP] - PEEP) of 20,25 , and $30 \mathrm{~cm} \mathrm{H}_{2} \mathrm{O}$ were measured and compared for the traditional tube and the SecureTube (size 7.5-mm inner diameter, cuffed). Similarly, the PIP required for the set $\mathrm{V}_{\mathrm{T}}$ of 500,600 , and $700 \mathrm{~mL}$ were measured for the traditional and SecureTube ETTs (7.5-mm inner diameter, cuffed). All experiments were repeated on 2 different test lungs (Respironics 1L test lung [Phillips, Murraysville, Pennsylvania] and Vital Signs 2L Breathing bag [Vital Signs, GE Health Care, Totowa, New Jersey]), with varying flows (for fixed $\mathrm{V}_{\mathrm{T}}$ ) of 30,40 , and $50 \mathrm{~L} / \mathrm{min}$ and with varying inspiratory times (for fixed $\Delta \mathrm{P}$ ) of $0.5,0.75$, and $1 \mathrm{~s}$. The absence of an air leak in the system was confirmed. Mean values at different set $\Delta \mathrm{P}$ and $\mathrm{V}_{\mathrm{T}}$ for both tubes $\left(\mathrm{V}_{\mathrm{T}}\right.$ and PIP, respectively) and difference in generated $V_{T}$ and PIPs at 3 different settings were compared. Mean values were compared by using the Student $t$ test, whereas differences in values at 3 settings were assessed by using analysis of variance. All measurements and analysis were done by two of us (ST and JS), with no involvement of the developer of the SecureTube (GD) to minimize the possibility of bias.

To evaluate if the added length and the side port would affect intubation time by experienced providers (physicians, advanced nurse practitioners [APNs], and respiratory therapists $[\mathrm{RTs}]$ ), we directly measured the time to

\footnotetext{
${ }^{1}$ United States Patent and Trademark Office March 2015 US 8,991,396 B2.
} 


\section{Flow Resistance and Placement of ETTs}

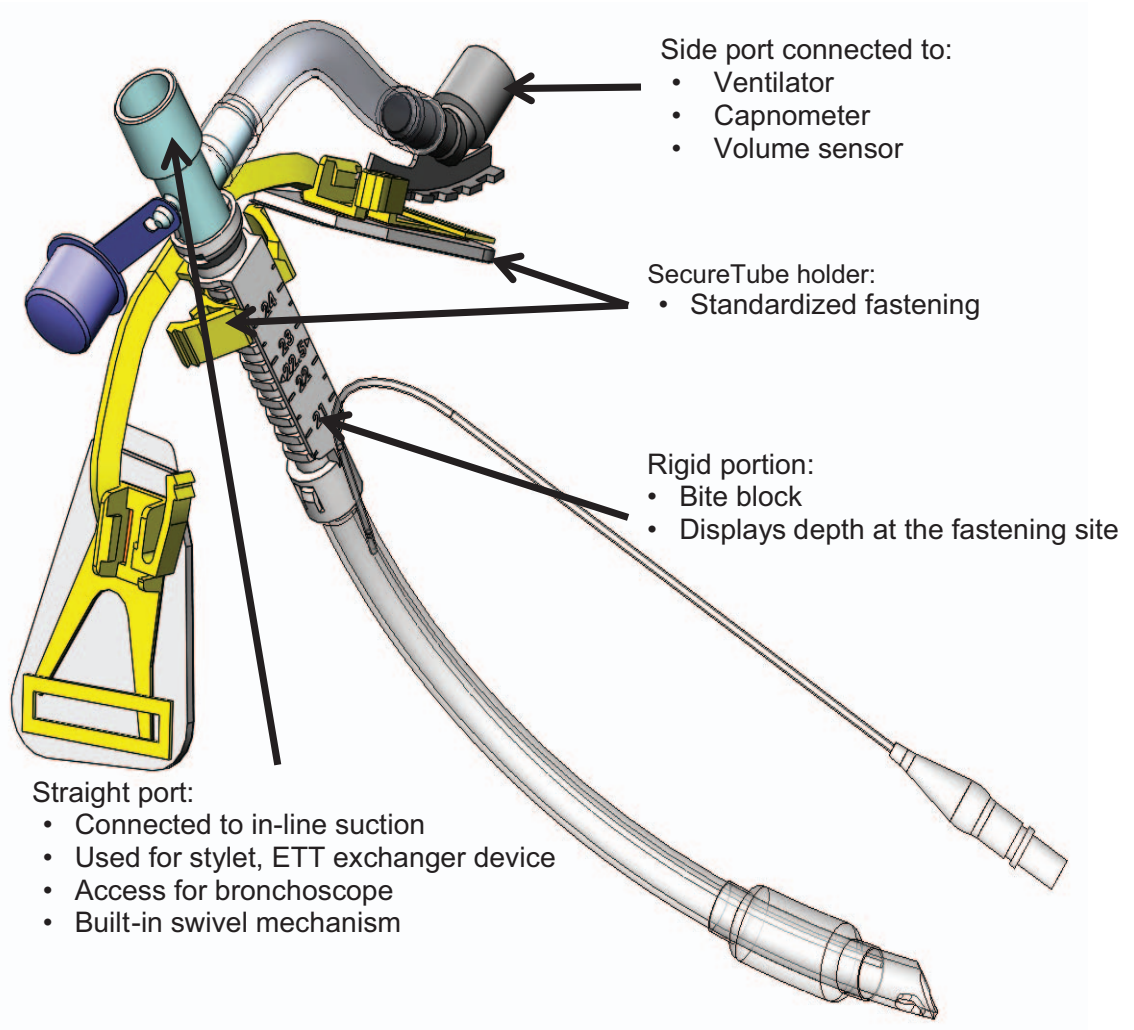

Fig. 1. The SecureTube design. ETT = endotracheal tube.

intubate on an adult mannikin by both traditional and the SecureTube. After viewing a 2-min introductory video of the SecureTube and its features, all the providers $(\mathrm{N}=11)$ completed intubation attempts. Each intubation was done in triplicate (for both the SecureTube and the standard tube, thus 6 intubation attempts by each provider). To prevent the impact of familiarization with the mannikin's airway on intubation times, the sequence (first intubation by using the SecureTube or by using the standard tube) was altered among the providers. The time was measured with a smart telephone clock by a single observer (ST) with a priori definition of start and end of intubation. At the end of the experiment, the providers were asked to complete an anonymous single question survey regarding their experience with intubation with the SecureTube on a Likert scale, with 1 being very easy and 5 being very difficult, compared with the standard ETT. The mean \pm SD times of intubation were compared by using the Wilcoxon and Kruskal-Wallis tests for both tubes. To assess the potential impact of varying skills between the physicians (intensivists and anesthesiologists) and other medical staff (APNs and RTs), intubation timings were separately analyzed for the 2 groups.

To assess the potential difficulty in securing the SecureTube and cognitive and physical challenges in adjusting the depth of insertion of the new tube, we used the NASA task load index as a survey tool. All APNs and RTs watched a 2-min introductory video that describes securement of the SecureTube and functionality of its ports before performing the next steps. The NASA task load index was completed by APNs and RTs after they had an opportunity to secure the tube, adjust the depth, and use the suction channel. The NASA task load index is a subjective work load assessment tool, which is used to evaluate work load on operators who work with various human-machine interface systems. It was developed in the 1980s by NASA Ames Research Center, and it is considered the accepted standard for measuring a subjective work load in a wide range of applications. ${ }^{14}$

For the purpose of this study, each provider was only asked to rank the 6 tasks on a scale of 1-21. The NASA task load index was completed on paper, and the values were later transferred to Excel (Microsoft, Redmond, Washington). The average rating for individual tasks among all the survey participants and mean cumulative scores for all tasks was calculated. Because pediatric and adult providers have very different work loads when securing ETTs (presumably much more difficult and stressful to secure and manipulate a pediatric ETT than an adult tube), we also analyzed the NASA task load index score separately for pediatric and adult providers. All statistical analyses 


\section{Flow Resistance and Placement of ETTs}

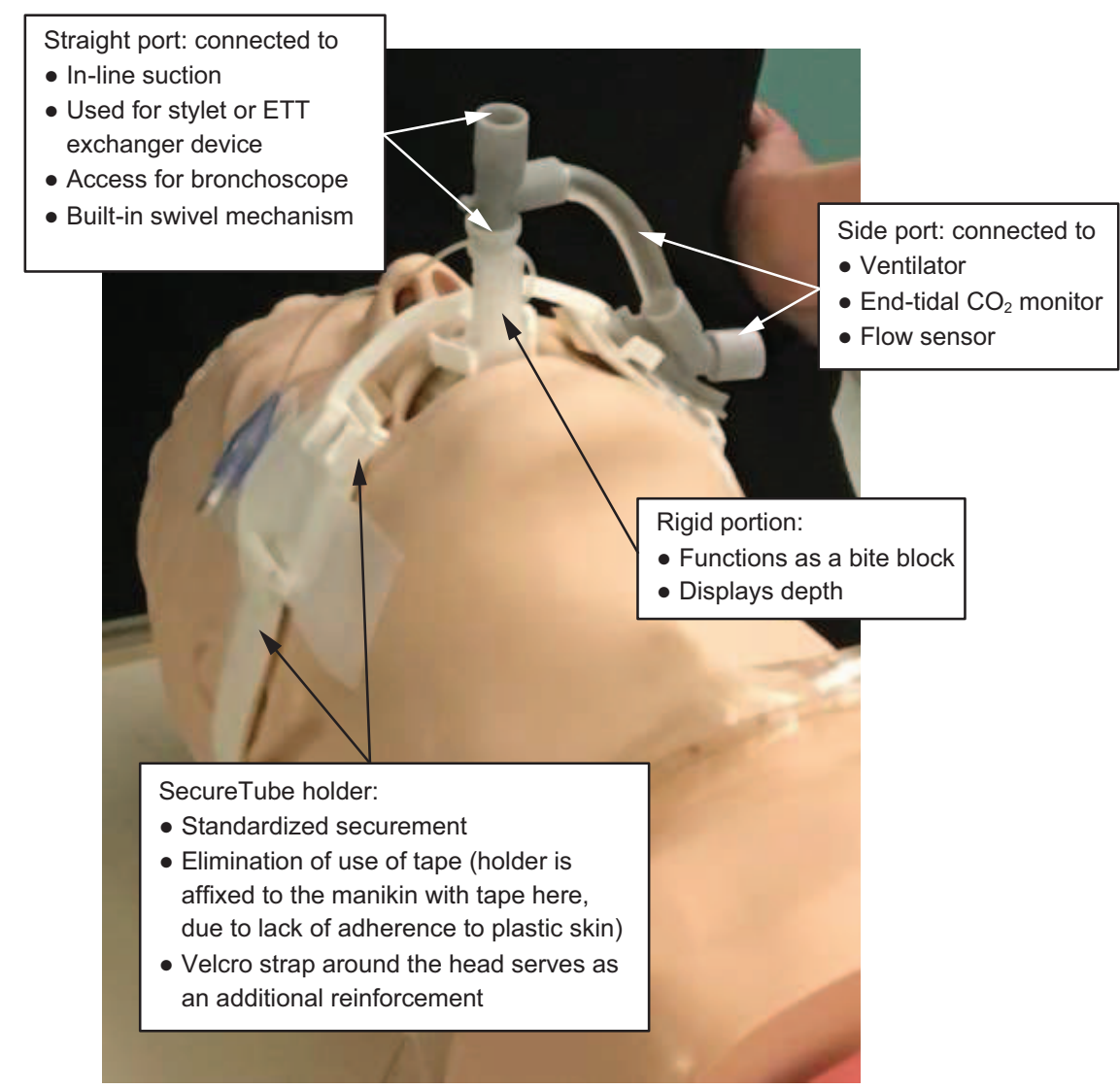

Fig. 2. The SecureTube in use. Tape was used in this photograph because self-adhesive patches did not adhere to the mannikin.

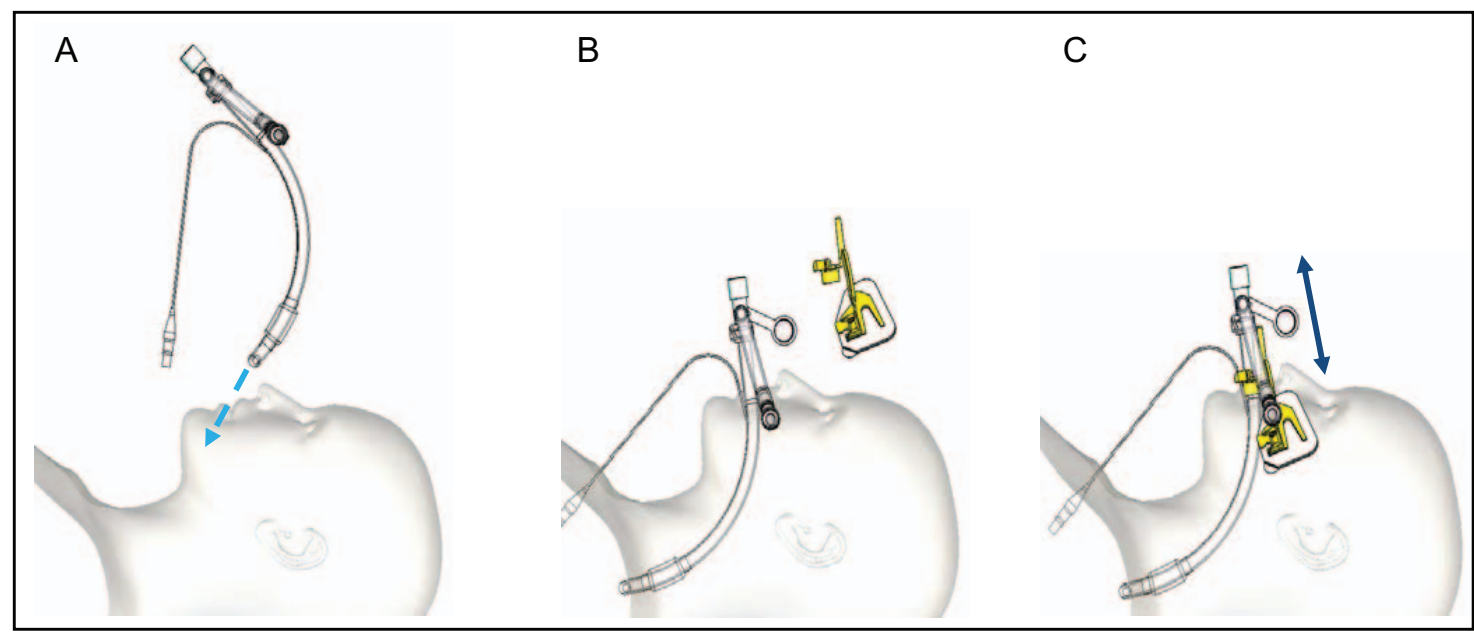

Fig. 3. The intubation process, with adjustment after radiographic confirmation. A: Intubate the patient. B: Affix the holder to the cheeks of the patient. C: Snap the side port into the holder, adjust the straight port to the desired position, and fix the straight port.

were performed by using JMP statistical software (SAS Institute, Cary, North Carolina). Standard descriptive and comparative analysis was performed with parametric (Student $t$ test) and non-parametric (Wilcoxon and KruskalWallis tests) as applicable.

\section{Results}

On flow-resistive studies, no significant difference was observed on average peak inspiratory pressures for different set $\mathrm{V}_{\mathrm{T}}$ or delivered $\mathrm{V}_{\mathrm{T}}$ for different pressure controls 


\section{Flow Resistance and Placement of ETTs}

Table 1. Flow Dynamic Comparison of the 2 Endotracheal Tubes (A) and Difference in Delivered $V_{T}$ and Peak Inspiratory Pressures for Different Pressure Controls and $V_{T}$ (B)

\begin{tabular}{|c|c|c|c|c|}
\hline & Variable & Standard Tube & SecureTube & $P^{*}$ \\
\hline \multirow[t]{8}{*}{$A$} & Set tidal volume $\dagger$ & & & \\
\hline & $500 \mathrm{~mL}$ & $28.3 \pm 2.4 \mathrm{~cm} \mathrm{H}_{2} \mathrm{O}$ & $29.5 \pm 2.5 \mathrm{~cm} \mathrm{H}_{2} \mathrm{O}$ & .43 \\
\hline & $600 \mathrm{~mL}$ & $30.1 \pm 1.6 \mathrm{~cm} \mathrm{H}_{2} \mathrm{O}$ & $31.3 \pm 1.9 \mathrm{~cm} \mathrm{H}_{2} \mathrm{O}$ & .28 \\
\hline & $700 \mathrm{~mL}$ & $32.1 \pm 1.3 \mathrm{~cm} \mathrm{H}_{2} \mathrm{O}$ & $33.3 \pm 2.0 \mathrm{~cm} \mathrm{H}_{2} \mathrm{O}$ & .27 \\
\hline & Set $\Delta$ pressure $\ddagger$ & & & \\
\hline & $20 \mathrm{~cm} \mathrm{H}_{2} \mathrm{O}$ & $253.3 \pm 66.5 \mathrm{~mL}$ & $236.6 \pm 59.2 \mathrm{~mL}$ & .65 \\
\hline & $25 \mathrm{~cm} \mathrm{H}_{2} \mathrm{O}$ & $365.0 \pm 89 \mathrm{~mL}$ & $326.6 \pm 86.8 \mathrm{~mL}$ & .46 \\
\hline & $30 \mathrm{~cm} \mathrm{H}_{2} \mathrm{O}$ & $476.6 \pm 127.6 \mathrm{~mL}$ & $410.0 \pm 113.3 \mathrm{~mL}$ & .35 \\
\hline
\end{tabular}

\begin{tabular}{|c|c|c|c|c|}
\hline & \multicolumn{2}{|c|}{$\begin{array}{c}\text { Difference in } \\
\text { Delivered Tidal Volume }\end{array}$} & Standard Error & $P \S$ \\
\hline \multirow[t]{3}{*}{ B } & $\begin{array}{l}20 \mathrm{~cm} \mathrm{H}_{2} \mathrm{O} \\
25 \mathrm{~cm} \mathrm{H}_{2} \mathrm{O} \\
30 \mathrm{~cm} \mathrm{H}_{2} \mathrm{O}\end{array}$ & $\begin{array}{l}16.6 \pm 17.5 \mathrm{~mL} \\
38.3 \pm 26.3 \mathrm{~mL} \\
66.6 \pm 31.4 \mathrm{~mL}\end{array}$ & 10.5 & \\
\hline & \multicolumn{3}{|c|}{ Difference in PIP Generated } & \\
\hline & $\begin{array}{l}500 \mathrm{~mL} \\
600 \mathrm{~mL} \\
700 \mathrm{~mL}\end{array}$ & $\begin{array}{l}1.16 \pm 0.75 \mathrm{~cm} \mathrm{H}_{2} \mathrm{O} \\
1.16 \pm 0.40 \mathrm{~cm} \mathrm{H}_{2} \mathrm{O} \\
1.16 \pm 0.98 \mathrm{~cm} \mathrm{H}_{2} \mathrm{O}\end{array}$ & 0.30 & $>.99$ \\
\hline \multicolumn{5}{|c|}{$\begin{array}{l}\text { * Student } t \text { test. } \\
\dagger \text { Average values for } 3 \text { different inspiratory times }(0.5,0.75 \text {, and } 1 \mathrm{~s}) \text { and } 2 \text { different bags } \\
\text { (Respironics and Vital Signs). } \\
\ddagger \text { Average values of } 3 \text { different flows }(30,40 \text {, and } 50 \mathrm{~L} / \mathrm{min}) \text { and } 2 \text { different kinds of bags } \\
\text { (Respironics and Vital Signs). } \\
\S \text { Analysis of variance. } \\
\mathrm{V}_{\mathrm{T}}=\text { tidal volume } \\
\text { PIP = peak inspiratory pressure }\end{array}$} \\
\hline
\end{tabular}

$(\Delta \mathrm{P})$, although the SecureTube tended toward higher peak pressure and slightly lower $\mathrm{V}_{\mathrm{T}}$. The difference in delivered $\mathrm{V}_{\mathrm{T}}$ at various settings between the 2 ETTs was larger at higher pressure control settings (from $16.6 \mathrm{~mL}$ at $20 \mathrm{~cm}$ $\mathrm{H}_{2} \mathrm{O}, 38.3 \mathrm{~mL}$ at $25 \mathrm{~cm} \mathrm{H}_{2} \mathrm{O}$ to $66.6 \mathrm{~mL}$ at $30 \mathrm{~cm} \mathrm{H}_{2} \mathrm{O}$, [standard error \pm 10.5 ] with lower $\mathrm{V}_{\mathrm{T}}$ for the SecureTube). This difference was statistically significant, with a $P=.01$ by analysis of variance. There was no difference in the PIP generated to deliver different $\mathrm{V}_{\mathrm{T}}$ with a mean \pm SD difference of $1.16 \pm 0.307 \mathrm{~cm} \mathrm{H}_{2} \mathrm{O}$, with a higher peak pressure with the SecureTube (Table 1).

A comparison of the mean time to intubate for all providers (33 separate attempts on both tubes by 11 providers) showed no significant difference (mean $11.1 \pm 4.8 \mathrm{~s}$ for traditional tube vs $9.9 \pm 3.5 \mathrm{~s}$ for the SecureTube, $P=.39$ ). A separate analysis for intubation attempts for APNs and RTs (all with traditional intubating responsibilities) and physicians also showed no significant difference (Table 2). All the participants in the intubation attempts ranked the difficulty of intubation with the SecureTube to be very easy compared with the standard tube (data not shown).

The work load in securing the tube, manipulating the depth, and suctioning with the SecureTube showed very low task loads on all 6 tasks (mental demand, physical
Table 2. Comparison of the Average Time to Intubate Between the 2 Tubes

\begin{tabular}{cccc}
\hline \hline Provider & $\begin{array}{c}\text { Traditional Tube, } \\
\text { Average } \pm \text { SD }(\mathrm{s})\end{array}$ & $\begin{array}{c}\text { SecureTube, } \\
\text { Average } \pm \mathrm{SD}(\mathrm{s})\end{array}$ & $P^{*}$ \\
\hline $\begin{array}{c}\text { Nurse practitioners and } \\
\text { respiratory therapists } \\
\text { Physicians (intensivists } \\
\text { and anesthesiologists) }\end{array}$ & $11.4 \pm 4.6$ & $10.2 \pm 2.9$ & .50 \\
$\begin{array}{l}\text { Overall } \\
\text { * Wilcoxon and Kruskal-Wallis tests. }\end{array}$ & $11.1 \pm 4.8$ & $9.6 \pm 3.9$ & .49 \\
\hline
\end{tabular}

demand, temporal demand, performance, effort, and frustration). The overall score for all the providers $(n=26,5$ RTs and 21 APNs from both pediatric and medical ICUs) for all domains was $3.04 \pm 1.9$ (on a scale of $1-21$ [ 1 is very low and 21 is very high demand]). The lowest score was for physical demand (mean $2.7 \pm 2.08$ ) and effort (mean $2.7 \pm 1.7$ ), while highest was for frustration (mean $3.1 \pm 2.8$ ). We separately analyzed scores for the pediatric providers and adult providers. Although the difference between them was not significant, pediatric providers generally gave higher task load with an overall mean \pm SD score of $3.8 \pm 2.5(n=11)$ versus $2.4 \pm 1.2$ for adult providers $(n=15)$ (Table 3$)$.

\section{Discussion}

The currently available ETTs are susceptible to unplanned extubation due to several factors. The SecureTube is designed to decrease unplanned extubation by providing 2 securing places. This required a significant change in design and deviation from the traditional shape. The addition of another port, a rigid portion at the bifurcation, and a different securing mechanism using special holder brought up concerns about user friendliness of SecureTube by the providers (Physicians, APNs, RTs and ICU nurses). The right-angle insertion of the side port raised the possibility of turbulence in the flow, with an effect on pressure or volumes provided by this tube.

We used the validated NASA task load index tool to study the effects of the different design of the SecureTube when securing it to the holder, suctioning, and moving the ventilator port from side to side by the APNs and RTs from pediatric and medical ICUs. This tool evaluated the effect on 6 tasks (mental demand, physical demand, temporal demand, performance, effort, and frustration) that could be affected by introduction of different securing and maintenance processes of the SecureTube. The results showed that the SecureTube posed a very low demand in all of the 6 domains and was comparable with the traditional tube experience. These results did not vary when adult providers were analyzed separately from the pediat- 
Table 3. NASA Task Load Index Scores

\begin{tabular}{lccccccc}
\hline \hline \multirow{2}{*}{ Provider } & \multicolumn{5}{c}{ NASA Task Load Index Score* } \\
\cline { 2 - 7 } & Mental Demand & Physical Demand & Temporal Demand & Performance & Effort & Frustration & Overall Score \\
\hline Pediatrics $(n=11)$ & $3.8 \pm 3.7$ & $3.4 \pm 2.6$ & $3.4 \pm 2.2$ & $4.2 \pm 3.1$ & $3.4 \pm 2.2$ & $4.5 \pm 3.6$ & $3.8 \pm 2.5$ \\
Adult $(n=15)$ & $2.4 \pm 1.6$ & $2.2 \pm 2.6$ & $2.9 \pm 1.8$ & $2.8 \pm 1.6$ & $2.2 \pm 1.2$ & $2.0 \pm 1.4$ & $2.4 \pm 1.2$ \\
$P^{*}$ & .51 & .33 & .59 & .28 & .17 & .065 & .21 \\
Overall & $3.03 \pm 2.7$ & $2.7 \pm 2.08$ & $3.15 \pm 2.0$ & $3.4 \pm 2.4$ & $2.7 \pm 1.7$ & $3.1 \pm 2.8$ & $3.04 \pm 1.9$ \\
& & & & & & \\
Results are mean \pm SD. Score range, $1-21$ (1 is very low and 21 is very high demand). \\
* Wilcoxon and Kruskal-Wallis tests.
\end{tabular}

ric providers; this supported that the process of securing as well as manipulating the SecureTube did not increase the complexity of tube management compared with the traditional ETT.

ETTs significantly contribute to air-flow resistance, which physiologically reflects the work imposed on the patient. ${ }^{15}$ Air-flow resistance has been measured in both in vitro models and in vivo settings. ${ }^{16}$ Several factors that contribute to airway resistance from the ETT include the diameter and length of the tube; flows; any deformation; secretions; and the geometry, particularly, the curvature. ${ }^{15,16}$ Standard tubes have an abrupt change in the crosssectional area at the tube adapter that connects the ventilator support tubing with the ETT, this has been shown to cause expiratory flow resistance values that are $10 \%$ larger than the inspiratory flow resistance values ${ }^{16,17}$; the SecureTube has a uniform internal diameter and thus potentially obviates this possibility.

However, we did measure a drop in the exhaled tidal volumes when using the SecureTube at comparable inspiratory pressures to the traditional tube. Although this was statistically significant, it can be mitigated by using higher pressures. The ventilator tubing connects to the side port of the SecureTube, which is at a $90^{\circ}$ angle to the main axis of the ETT. There is a theoretical concern that the right angle could result in turbulenct air flow and cause a further increase in the resistance; however, a previous study showed only a $3 \%$ increase in the airway resistance when the ETT was curved at $90^{\circ} .{ }^{18}$ In addition, it has been shown that the geometry of the tube affects the turbulence, such that a curved tube may allow the laminar flow at a Reynolds number, which otherwise would suggest turbulence if the tube were straight. ${ }^{19}$

The current study had several limitations: (1) it was single center study, (2) used only one size of ETT (7.5-mm inner diameter) for the comparison, (3) was performed in simulated settings by using the mannikin and test lungs, and (4) we did not study the effect of the side port on the possible addition of dead space to the ventilator circuit. The mannikin plastic skin posed a challenge during securement with tape or another adhesive method and caused difficulty in interpretation of the effectiveness of securement for both the traditional tube and the SecureTube.

\section{Conclusions}

The SecureTube performed equally well in subjective and objective evaluations when compared with the traditional tube. The providers reported a very easy process of intubation, and the different design did not pose any additional burden during its securement, manipulation, or maintenance.

\section{REFERENCES}

1. Boulain T. Unplanned extubations in the adult intensive care unit: a prospective multicenter study. Association des Reanimateurs du CentreOuest. Am J Respir Crit Care Med 1998;157(4 Pt 1):1131-1137.

2. Fitzgerald RK, Davis AT, Hanson SJ. Multicenter Analysis of the Factors Associated With Unplanned Extubation in the PICU. Pediatr Crit Care Med 2015;16(7):e217-e223.

3. Chevron V, Ménard JF, Richard JC, Girault C, Leroy J, Bonmarchand G. Unplanned extubation: risk factors of development and predictive criteria for reintubation. Crit Care Med 1998;26(6):1049-1053.

4. Epstein SK, Nevins ML, Chung J. Effect of unplanned extubation on outcome of mechanical ventilation. Am J Respir Crit Care Med 2000;161(6): 1912-1916.

5. Listello D, Sessler CN. Unplanned extubation. Clinical predictors for reintubation. Chest 1994;105(5):1496-1503.

6. Tripathi S, Nunez DJ, Katyal C, Ushay HM. Plan to Have No Unplanned: A Collaborative, Hospital-Based Quality-Improvement Project to Reduce the Rate of Unplanned Extubations in the Pediatric ICU. Respir Care 2015;60(8):1105-1112.

7. Lucas da Silva PS, de Carvalho WB. Unplanned extubation in pediatric critically ill patients: a systematic review and best practice recommendations. Pediatr Crit Care Med 2010;11(2):287-294.

8. Popernack ML, Thomas NJ, Lucking SE. Decreasing unplanned extubations: utilization of the Penn State Children's Hospital Sedation Algorithm. Pediatr Crit Care Med 2004;5(1):58-62.

9. da Silva PS, de Aguiar VE, Neto HM, de Carvalho WB. Unplanned extubation in a paediatric intensive care unit: impact of a quality improvement programme. Anaesthesia 2008;63(11):1209-1216.

10. Kaufman J, Rannie M, Kahn MG, Vitaska M, Wathen B, Peyton C, et al. An interdisciplinary initiative to reduce unplanned extubations in pediatric critical care units. Pediatrics 2012;129(6):e1594-e1600.

11. Maguire GP, DeLorenzo LJ, Moggio RA. Unplanned extubation in the intensive care unit: a quality-of-care concern. Crit Care Nurs Q 1994;17(3):40-47. 


\section{Flow Resistance and Placement of ETTs}

12. Grap MJ, Glass C, Lindamood MO. Factors related to unplanned extubation of endotracheal tubes. Crit Care Nurse 1995;15(2):57-65.

13. Fisher DF, Chenelle CT, Marchese AD, Kratohvil JP, Kacmarek RM. Comparison of commercial and noncommercial endotracheal tube-securing devices. Respir Care 2014;59(9):1315-1323.

14. Hart SG. Nasa-Task Load Index (NASA-TLX); 20 Years Later. Proc Hum Factors Ergon Soc Annu Meet 2006;50(9):904-908. https://humanfactors.arc.nasa.gov/groups/TLX/downloads/HFES_2006_Paper.pdf. Accessed April 29th 2018.

15. Straus C, Louis B, Isabey D, Lemaire F, Harf A, Brochard L. Contribution of the endotracheal tube and the upper airway to breathing workload. Am J Respir Crit Care Med 1998;157(1):23-30.
16. Wright PE, Marini JJ, Bernard GR. In vitro versus in vivo comparison of endotracheal tube airflow resistance. Am Rev Respir Dis 1989;140(1):10-16.

17. Guttmann J, Kessler V, Mols G, Hentschel R, Haberthür C, Geiger $\mathrm{K}$. Continuous calculation of intratracheal pressure in the presence of pediatric endotracheal tubes. Crit Care Med 2000;28(4): 1018-1026.

18. Wall MA. Infant endotracheal tube resistance: effects of changing length, diameter, and gas density. Crit Care Med 1980;8: 38-40.

19. Ward-Smith AJ. Internal Fluid Flow: the fluid dynamics of flow in pipes and ducts. Oxford: Oxford University Press; 1980. 